\title{
COMPARISON OF PHOSPHORUS LEACHING ON DIFFERENT SOILS TO TUNING IEEPAGRDLM MODEL
}

Igor Subbotin, Alexander Briukhanov, Aleksandr Ogluzdin

Institute for Engineering and Environmental Problems in Agricultural Production, Russia

itmo1652@mail.ru

\begin{abstract}
Laboratory study of phosphorus leaching from the plow horizon was conducted. The purpose of the study is to examine and compare the values of leaching phosphorus mass from the plow horizon in order to obtain the values of the coefficients for the IEEPAgrDLM model (Agricultural Diffuse Load Model by IEEP the Institute for Engineering and Environmental Problems). The IEEPAgrDLM model allows to calculate the diffuse load on water bodies from agricultural fields depending on the field area, field soil nutrient content, type of soil by mechanical composition, doses of mineral and organic fertilizers, structure of crop rotation and distance from the field to the nearest water body. The influence of soil factors was studied. In the experiment 4 types of soil of different mechanical composition were used. Triplicate repeatability was used - for each type of soil, three vessels were used. The laboratory installation was a rack with vessels filled with soil. The vessels have a cover for introduction of water at the top and the filter element, bung with a glass tube and stopper at the bottom. During the study, once every two weeks, water was poured into the vessels and water which passed through the soil was taken. The volumes of water passed through the soil were measured and the concentrations of phosphorus and nitrogen in the water were analyzed. Based on the results of a six-month experiment (from April to October 2017), the values of the masses of nitrogen and phosphorus washed from the vessels were obtained. In this article, the results of the experiment on phosphorus are considered. The processing of laboratory data made it possible to calculate the coefficients reflecting the dependence of the mass of phosphorus leaching on the type of soils, which were used to update the coefficient values of the IEEPAgrDLM model.
\end{abstract}

Keywords: phosphorus, soil, modelling, water protect, phosphorus leaching.

\section{Introduction}

The topic of water protection is currently very relevant. And there is a need for practical tools to assess the negative impact on water bodies at the farm level. One such tool is the IEEPAgrDLM model. This model (Agricultural Diffuse Load Model by IEEP - the Institute for Engineering and Environmental Problems) allows to calculate the diffuse load on water bodies from agricultural fields. This model was created on the basis of theoretical studies and initially its coefficients were obtained on the basis of literary sources. The goal of this study was to investigate the properties of the four most common soils in the Leningrad Oblast region in order to refine the corresponding coefficients of the model, which will improve the model's accuracy for the Leningrad Oblast region. Leningrad region is an area of the most intensive livestock production in the Russian part of the Baltic Sea region. The soil samples used in the experiment were taken from the arable horizon of actively used crop fields.

\section{The IEEPAgrDLM model}

Diffuse load of nitrogen and phosphorus depends on the farm specialisation, type and structure of soils, crop rotation, technologies of applied mineral and organic fertilisers.

Two sources of nitrogen and phosphorus removal are considered to determine the diffuse load: soil and fertilisers (mineral and organic). The leaching from farmland soils is calculated taking into account the depth of the arable and root zones, which is $20-25 \mathrm{~cm}$ for the Russian part of the Baltic Sea Region. Significantly prevailing part of nitrogen and phosphorus leaching occurs precisely from this soil layer.

According to the methodology developed by the IEEP, the nutrient input to the water bodies from the farm fields (Lagr, t/yr) is calculated by the formula:

$$
L_{\text {agr }}=\sum_{i} A_{i}\left(M_{\text {soili }} K_{1}+\left(\alpha_{1} M_{\min i}+\alpha_{2} M_{\text {orgi }}\right) K_{6}\right) K_{2} K_{3} K_{4} K_{5} / 1000
$$

where $M_{\text {soili }}-$ nutrient content in the arable soil layer, $\mathrm{kg} \cdot \mathrm{ha}^{-1}$;

$M_{\min i}$ and $M_{\text {orgi }}$ - application rates of mineral and organic fertilisers on the fields of the $i$-th agricultural enterprise, $\mathrm{kg} \cdot \mathrm{ha}^{-1}$;

$A_{i}$ - land area of the $i$-th agricultural enterprise, ha;

$\alpha_{1}-$ coefficient of the plant uptake of nutrients from mineral fertilisers; 
$\alpha_{2}$ - coefficient of the plant uptake of nutrients from organic fertilisers;

$K_{1}$ - coefficient of nutrients leaching from the arable soil layer;

$K_{2}$ - distance coefficient between the farm land and the water body;

$K_{3}$ - coefficient of the soil type (by its origin);

$K_{4}$ - coefficient of the soil texture;

$K_{5}$ - coefficient, which takes into account the structure of farmland, i.e. ratio of arable land, perennial grasses, meadows, pastures;

$K_{6}$ - coefficient, which takes into account the introduction of BAT (best available technology).

All coefficients are dimensionless. Values of the coefficients were determined on the basis of an integrated analysis of literature sources [1-4] and the IEEP experimental data and were further used to calculate the nutrient load from farmland in the North-West Russia (Table 1).

The values of the model coefficients for North-West Russia

Table 1

\begin{tabular}{|c|c|c|}
\hline Coefficient & $\boldsymbol{N}$ & $\boldsymbol{P}$ \\
\hline$\alpha_{1}$ & 0.3 & 0.03 \\
\hline$\alpha_{2}$ & 0.1 & 0.02 \\
\hline$K_{1}$ & 0.03 & 0.008 \\
\hline$K_{2}$ (from 50 to 500 m) & 0.6 & 0.6 \\
\hline$K_{2}$ (from 500 to 2000 m) & 0.2 & 0.2 \\
\hline$K_{2}$ (above 2000 m) & 0.1 & 0.1 \\
\hline$K_{3}$ (soddy podzolic soil) & 1.0 & 1.0 \\
\hline$K_{3}$ (carbonate soil) & 1.2 & 1.4 \\
\hline$K_{3}$ (peat soil) & 0.8 & 1.0 \\
\hline$K_{4}$ (heavy-textured soils) & 1.0 & 1.0 \\
\hline$K_{4}$ (light-textured soils) & 1.8 & 2.0 \\
\hline$K_{5}$ (cattle breeding) & 0.46 & 0.37 \\
\hline$K_{5}$ (crop production) & 0.88 & 0.76 \\
\hline$K_{5}$ (poultry breeding) & 0.46 & 0.37 \\
\hline$K_{5}$ (pigs breeding) & 0.46 & 0.37 \\
\hline$K_{6}$ (without applying BAT) & 1.0 & 1.0 \\
\hline$K_{6}$ (with BAT) & 0.25 & 0.1 \\
\hline
\end{tabular}

To determine the basic coefficients, which define the share of nitrogen and phosphorus leaching, the characteristics of sod-podzolic soils were taken as the basis because they are the most common type on the studied areas. The average nutrient removal with the crop yield was taken as $120 \mathrm{~kg} \cdot \mathrm{ha}^{-1}$ for nitrogen and $17.6 \mathrm{~kg} \cdot \mathrm{ha}^{-1}$ for phosphorus.

The more detailed description of the model and the example of its application can be found in the article of the authors of the model [5].

\section{Materials and methods}

The basis of the experimental method is the classical experimental approach to evaluate the ability of the soil mineralization [6]. The laboratory installation that was used is a set of vessels in the rack. Each vessel has a cover, bung with a glass tube, a stopper and it contains a filter layer (Fig. 1). The height of the vessels is $220 \mathrm{~mm}$. The height of the soil layer in the vessel corresponded to the range of the heights of the arable horizons in the region and amounted to $200 \mathrm{~mm}$.

The essence of laboratory studies consisted in washing the soil samples differing in their mechanical composition. Washing (flushing) was performed at intervals of once every two weeks. The amount of initial flushing water was calculated based on the average annual rainfall in the region and amounted to $174 \mathrm{ml}$ per vessel per flushing. After each flushing, the volume of water that passed through the soil and left the vessel was fixed for each vessel. The water that left each vessel was analyzed for phosphorus content. The amount of leaching phosphorus was determined by multiplying the volume of water that left the vessel and the phosphorus content. 

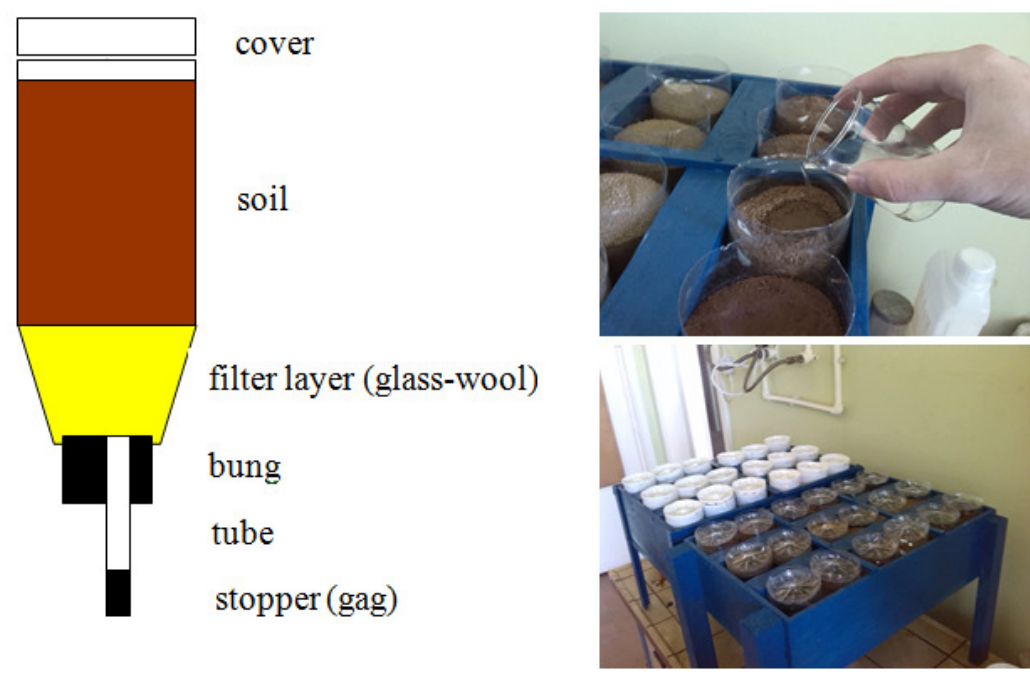

Fig. 1. Laboratory installation

In the experiment, four types of soil were used: sand, sandy, loamy and clay, and two kinds of organic fertilizers. Fertilizer 1 (low mineralized organic fertilizer) - matured within 3 months poultry manure - a typical fertilizer widely used for the region. The second organic fertilizer (with a higher mineralization of nutrients) is a little-used but promising fertilizer obtained from the same poultry manure with the help of an accelerated composting (biofermentation technology). Main results were obtained according to the soil with fertilizer 1 . The results for the soil with fertilizer 2 will be used to predict changes in the situation of removal of nutrients to water at the transition to the use of fertilizer 2. The results for the soil without fertilizers will be used for unused agricultural fields, on which fertilizers are not used.

Doses of organic fertilizers added to the soil were calculated in accordance with the doses applied in the fields from which the soils for the experiment were obtained. The average dose of fertilizers corresponded to $31.1 \mathrm{~kg}$ of phosphorus per hectare. For the soil surface area in the vessel $\left(50.24 \mathrm{~cm}^{2}\right)$, this dose corresponds to $0.016 \mathrm{~g}$ of phosphorus.

Variants of the experiment (contents of the vessels):

1. sandy soil without fertilizer application;

2. sandy loam soil without fertilizer application;

3. loamy soil without fertilizer application;

4. clay soil without fertilizer application;

5. sandy soil with organic fertilizer 1 ;

6. soil sandy loam with organic fertilizer 1 ;

7. loamy soil with organic fertilizer 1 ;

8. clay soil with organic fertilizer 1 ;

9. sandy soil with organic fertilizer 2;

10. sandy loam soil with organic fertilizer 2;

11. loam soil with organic fertilizer 2;

12. clay soil with organic fertilizer 2 .

The repetition of the experiment is threefold (each variant was duplicated in three vessels). Total number of vessels is 36 pieces.

\section{Results and discussion}

In the course of the research, 11 flushes were carried out (from April to October 2017).

After the completion of all flushes, the data on the leached phosphorus were processed: data on 5 vessels with abnormal water infiltration were removed. For 3 vessels in some flushes leak was stopped and water was standing in the upper part of the vessel before evaporating over several days. In 2 vessels, on the contrary - the soil was severely cracked and water flowed through the cracks too 
quickly - slightly leaching away the nutrients. The rest data were averaged - the average values were obtained from the values of the vessels with the same contents. These values are given in Table 2, the graph is shown in Figure 2.

Table 2

Average amounts of leached phosphorus mass for each flushing (in mg)

\begin{tabular}{|c|c|c|c|c|c|c|c|c|c|c|c|c|}
\hline & \multicolumn{10}{|c|}{ Index numbers of flushing (\#1 - first flushing) } & $\begin{array}{c}\text { Total } \\
\text { sum, } \\
\text { mg }\end{array}$ \\
\cline { 2 - 13 } & $\mathbf{\# 1}$ & $\mathbf{\# 2}$ & $\mathbf{\# 3}$ & $\mathbf{\# 4}$ & $\mathbf{\# 5}$ & $\mathbf{\# 6}$ & $\mathbf{\# 7}$ & $\mathbf{\# 8}$ & $\mathbf{\# 9}$ & $\mathbf{\# 1 0}$ & $\mathbf{\# 1 1}$ & $\mathbf{1 0}$ \\
\hline sandy soil & 6.98 & 6.18 & 4.65 & 4.20 & 3.38 & 2.87 & 1.61 & 0.64 & 0.17 & 0.07 & 0.07 & 30.69 \\
\hline sandy loam soil & 6.49 & 4.48 & 3.92 & 3.18 & 1.72 & 1.57 & 0.94 & 0.13 & 0.06 & 0.05 & 0.05 & 22.49 \\
\hline loamy soil & 5.53 & 3.43 & 2.52 & 2.14 & 1.62 & 1.25 & 0.64 & 0.41 & 0.15 & 0.14 & 0.06 & 17.69 \\
\hline clay soil & 4.30 & 2.89 & 1.95 & 1.72 & 1.38 & 0.70 & 0.37 & 0.09 & 0.05 & 0.08 & 0.07 & 13.45 \\
\hline
\end{tabular}

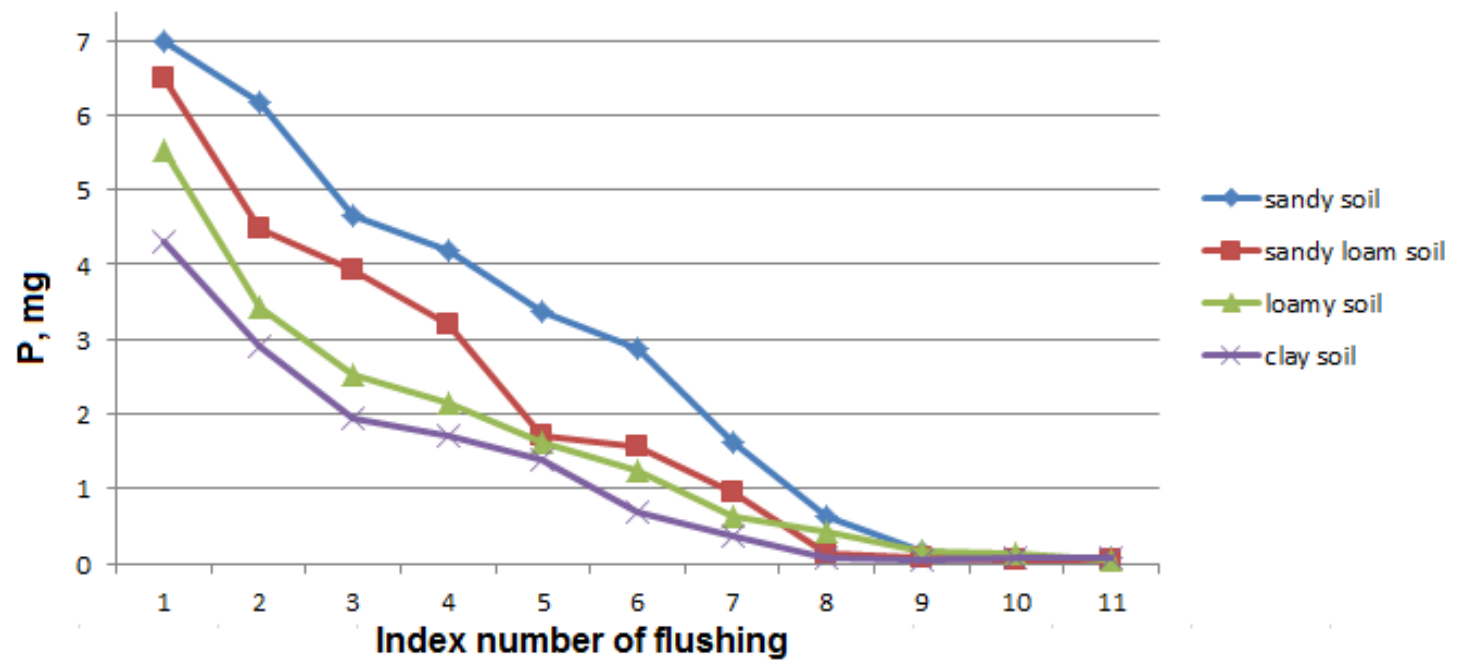

Fig. 2. Dynamics of changes of leaching phosphorus mass from the soil

Analysis of the results of laboratory studies allowed to confirm the presence of dependencies between the type of soil and the rate of leaching of phosphorus and express them in the form of numerical coefficients. The existing values of the IEEPAgrDLM model coefficient $\mathrm{K}_{4}$, characterizing the leaching of nutrients depending on the mechanical composition of the soil, imply a division into heavy and light soils. Therefore, similar coefficients were formed on the basis of the obtained experimental data. For heavy soils, the coefficient was obtained as average values of clayey and loamy soils, for light soils - as average values of sandy and sandy loamy soils. The ratio between the existing coefficients for light and heavy soils is $1: 2$. The value of 1 corresponds to the most widespread in the region heavy soils. The calculation of the corresponding ratio for the new data is given in expression (2).

$$
\frac{K_{4} l t}{K_{4} h t}=\frac{(M s+M s l) / 2}{(M l+M c) / 2}=\frac{(30.69+22.49) / 2}{(17.69+13.45) / 2}=\frac{26.59}{15.57}=1.7
$$

where $K_{4} l t-$ value of the $K_{4}$ coefficient for light-textured soils,

$K_{4} h t$ - value of the $\mathrm{K}_{4}$ coefficient for heavy-textured soils,

$M s, M s l, M l, M c$ - value of leached phosphorus mass for sandy, sandy loamy, loamy and clay soils.

Thus, the $K_{4}$ coefficient value for light-textured soils for more precision is defined as "1.7" and this value can be used instead of the old value of "2.0". The difference between the new value (1.7) and the old value (2.0) is $15 \%$. It is also possible to increase the accuracy of the model using the $K_{4}$ coefficient values not for heavy and light soils, but for sandy soil, sandy loam soil, loamy soil, clay soil. 
Obtaining respective values of the coefficient $K_{4}$ is given below:

$$
\begin{aligned}
& K_{4} s=\frac{M s}{(M l+M c) / 2}=\frac{30.69}{(17.69+13.45) / 2}=\frac{30.69}{15.57}=1.97 \\
& K_{4} s l=\frac{M s l}{(M l+M c) / 2}=\frac{22.49}{(17.69+13.45) / 2}=\frac{22.49}{15.57}=1.44 \\
& K_{4} l=\frac{M l}{(M l+M c) / 2}=\frac{17.69}{(17.69+13.45) / 2}=\frac{17.69}{15.57}=1.14 \\
& K_{4} c=\frac{M c}{(M l+M c) / 2}=\frac{13.45}{(17.69+13.45) / 2}=\frac{13.45}{15.57}=0.86
\end{aligned}
$$

where $K_{4} s, K_{4} s l, K_{4} l, K_{4} c$ - value of the $K_{4}$ coefficient for sandy, sandy loamy, loamy and clay soils.

\section{Conclusions}

1. The data obtained in the experiment quantitatively showed the difference in the leaching of phosphorus from soils of different mechanical composition for the Leningrad Oblast region.

2. The data obtained in the experiment made it possible to clarify the value of the $K_{4}$ coefficient of the IEEPAgrDLM model for the light soils of the Leningrad Oblast region. The difference between the new value (1.7) and the old value (2.0) is $15 \%$.

3. Also, more accurate values of the coefficient were obtained for sandy, sandy loam, loamy and clay soils of the Leningrad Oblast region. The resulting coefficients allow obtaining more reliable data using the IEEPAgrDLM model.

\section{References}

[1] Минеев В. Г. Агрохимия (Agrochemistry). Publishing house of Moscow State University, 2006, 752 p. (In Russian).

[2] Кидин В. В., Торшин С. П. Агрохимия. Учебник (Agrochemistry. Tutorial). Publishing house "Prospekt", 2015, 619 p. (In Russian).

[3] Barbosa, F. T., Bertol, I., Luciano, R. V., Gonzalez, A. P.. Phosphorus losses in water and sediments in runoff of the water erosion in oat and vetch crops seed in contour and downhill. Soil and Tillage Research, 106(1), 2009, pp. 22-28.

[4] Djodjic F., Börling K., Bergström L. Phosphorus leaching in relation to soil type and soil phosphorus content. Journal of Environmental Quality, 2004. T. 33, №. 2. pp. 678-684.

[5] Briukhanov A., Kondratyev S., Tarbaeva V., etc. Contribution of agricultural sources to nutrient load generated on the Russian part of the Baltic sea catchment area. Proceedings of the 8th International Scientific Conference Rural Development 2017. November 23-24, 2017, Akademija, Kaunas distr., Lithuania, pp. 226-231.

[6] Gregorich E. G., Carter M. R. Soil sampling and methods of analysis. - CRC Press, 2007, 1264 p. 